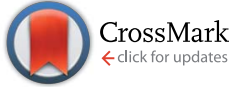

Cite this: RSC Adv., 2017, 7, 6018

Received 23rd November 2016 Accepted 7th January 2017

DOI: $10.1039 / c 6 r a 27201 \mathrm{k}$

www.rsc.org/advances

\section{Cul promoted sulfenylation of organozinc reagents with arylsulfonyl chlorides $\uparrow$}

\author{
Ying Fu, ${ }^{*}$ Yuhu Su, Qin-shan Xu, Zhengyin Du, Yulai Hu, Ke-Hu Wang \\ and Danfeng Huang
}

A Cul promoted sulfenylation of organozinc reagents with arylsulfonyl chlorides/PPh 3 has been explored. This reaction proceeded smoothly through an alkyl/aryl radical (generated from organometallics) under mild conditions and produced the desired sulfide products in excellent yields.
Thioether is a very important structural motif in numerous natural products and bioactive molecules, and is widely used as a versatile building block in organic molecules. As a consequence, novel synthetic protocols have been continuously developed $^{1}$ and much of recent attention has focused on exploitation environmental friendly, thiol-free materials such as Bunte Salts, ${ }^{2}$ potassium ethyl xanthogenate $,{ }^{3} \mathrm{NaS}_{2} \mathrm{O}_{3},{ }^{4} \mathrm{KSCN},{ }^{5}$ $\mathrm{CS}_{2},{ }^{6}$ sulfonyl hydrazides, ${ }^{7} \mathrm{DMSO}^{8}$ and $N$-(aryl/alkylthio)succinimides ${ }^{9}$ etc. as the sulfur source.

Recently, arylsulfonyl chloride, considering its abundance and inexpensiveness, has emerged as a promising thiol-free sulfur source in thioether synthesis. In 2011, You et al. first demonstrated that arylsulfonyl chlorides can be employed as sulfur source for sulfenylation of electron-rich arenes or heteroarenes..$^{10}$ This promising sulfenylation protocol was quickly recognized and was further enlarged in sulfenylation of (hetero) arenes in PEG-400, ${ }^{11}$ quinones ${ }^{12}$ and iodoarenes. ${ }^{13}$ However, these methodologies are limited to diaryl sulfide synthesis and require high temperature.

Organozinc reagents are mild organometallics and were used extensively in organic synthesis. ${ }^{14}$ However, these privileged organometallics have rarely been employed in C-S bond formation reactions unless a reactive sulfur electrophile such as sulfenyl chlorides ${ }^{15}$ or $\mathrm{SO}_{2}$ (ref. 16) etc. were introduced as the substrates. Previously, we developed a CuI catalyzed synthesis of arylsulfones from organozinc reagents and arylsulfonyl chlorides. ${ }^{17}$ During this study, we accidentally found that when $\mathrm{PPh}_{3}$ was employed as the ligand, thioether can be formed unexpectedly. Owing to our interests on the synthesis and application of organozinc reagents in organic synthesis, ${ }^{18}$ we here report an CuI promoted sulfenylation of organozinc reagents employing commercially available arylsulfonyl chlorides as the sulfur source under mild reaction (Scheme 1).

College of Chemistry and Chemical Engineering, Northwest Normal University, Lanzhou, Gansu 730070, P. R. China. E-mail: fuying@iccas.ac.cn; Fax: +86-9317971989; Tel: +86-931-7971533

$\dagger$ Electronic supplementary information (ESI) available. See DOI: $10.1039 / \mathrm{c} 6 \mathrm{ra} 27201 \mathrm{k}$
At the outset of this investigation, optimization of the reaction parameters was performed using phenylzinc bromide 1a and $p$-tolylsulfonyl chloride $\mathbf{2 a}$ as the model substrates (Table 1). When the reaction was conducted by adding $p$-tolylsulfonyl chloride 2a into phenylzinc bromide 1a in the presence of CuI (1.0 equiv.) and $\mathrm{PPh}_{3}$ (2.2 equiv.) in THF at room temperature, phenyl $p$-tolyl sulfone was formed in $68 \%$ isolated yield without formation of any sulfides product. Alternatively, when phenylzinc bromide 1a was added into a mixture of $p$ tolylsulfonyl chloride $\mathbf{2 a}$ and $\mathrm{PPh}_{3}$ (2.2 equiv.) in the presence of CuI (1.0 equiv.) in THF at room temperature, $p$-tolyl disulfide $4 \mathbf{a}$ was obtained in nearly quantitative yield (95\%, entry 1$)$. The appearance of disulfide $\mathbf{4 a}$ can be ascribed to immediate reduction of $p$-tolylsulfonyl chloride $2 \mathrm{a}$ by $\mathrm{PPh}_{3} \cdot{ }^{19}$ However, this experimental result also illustrates the fact that organozinc reagents are inert organometallic species towards organodisulfides. To further improve the reactivity of organozinc reagents, two equivalents of TMEDA (tetramethylethylenediamine, L1) was added and heating to reflux overnight, the yield of 3a was improved to $35 \%$ (entry 2). Replacement of CuI with

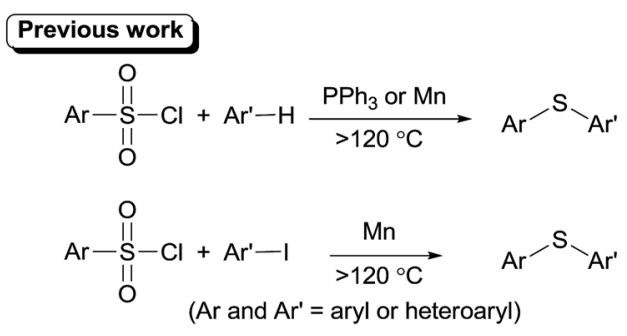

This work

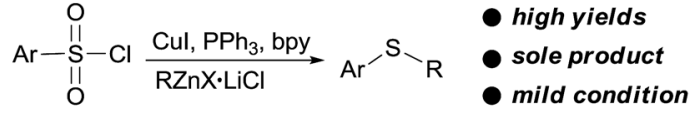

$$
\begin{aligned}
& \text { ( } \mathrm{Ar}=\text { aryl or heteroaryl; } \mathrm{R}=\text { aryl, heteroaryl, allyl, alkyl...) }
\end{aligned}
$$

Scheme 1 Approaches toward transformation of sulfonyl chlorides into thioethers. 
Table 1 Optimization of the reaction conditions ${ }^{a}$

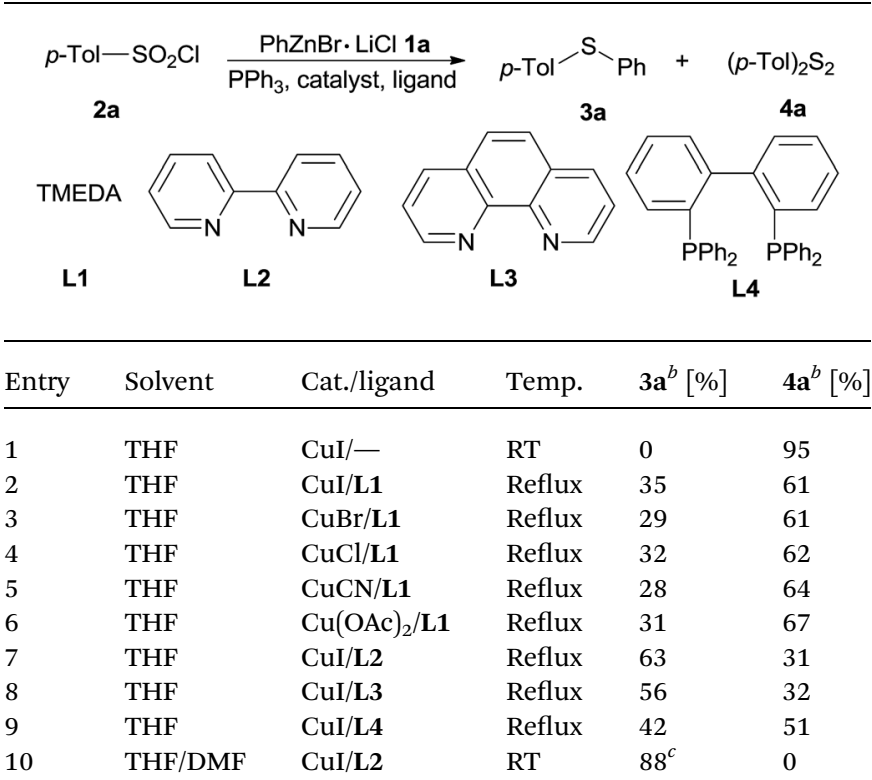

${ }^{a}$ Reaction conditions: 1 a $(2 \mathrm{mmol})$ in THF ( $\left.4 \mathrm{~mL}\right)$ was added into a THF $(4 \mathrm{~mL})$ solution containing catalyst $(1.0 \mathrm{mmol})$, ligand $(2.0 \mathrm{mmol}), 2 \mathrm{a}$ $(1.0 \mathrm{mmol})$ and $\mathrm{PPh}_{3}(2.2 \mathrm{mmol})$ under argon atmosphere and was then stirred overnight. ${ }^{b}$ Isolated yields. ${ }^{c} 1.0 \mathrm{~mL}$ of DMF was added.

other cuprous salts such as $\mathrm{CuBr}, \mathrm{CuCl}, \mathrm{CuCN}$ and $\mathrm{Cu}(\mathrm{OAc})_{2}$ are all effective, albeit without obvious yield improvement (entries 3-6). Ligands L1-L4 screening showed that bipyridine (L2) was the best one, enhancing the yield of 3a to 63\% (entries 7-9). Organozinc reagents exhibit enhanced reactivity in a polar aprotic solvent, e.g. DMF. ${ }^{20}$ Gratifyingly, the use of THF-DMF $(8: 1, \mathrm{v} / \mathrm{v})$ as a solvent dramatically improved the yield of $3 \mathbf{a}$ to $88 \%$ yield and disulfides 4 a was cleanly consumed at room temperature after 12 hours (entry 10).

Although classic reactive organometallics such as Grignards, ${ }^{21}$ organolithium reagents ${ }^{22}$ and some mild organometallic species such as aryltrimethoxysilanes ${ }^{23}$ and triarylbismuthanes $^{\mathbf{2 4}}$ are able to convert disulfides into sulfides, there are some apparent problems relating to these protocols. Grignards and organolithium reagents will simultaneously cleave both $\mathrm{C}-\mathrm{S}$ and $\mathrm{S}-\mathrm{S}$ bonds of disulfides, ${ }^{25}$ thus are limited in practical sulfides synthesis. On the other hand, triarylbismuthanes $^{26}$ and aryltrimethoxysilanes ${ }^{27}$ themselves were prepared from corresponding Grignards, therefore, precludes existence of some important functional groups on these reagents. In this respect, our organozinc protocol ${ }^{28}$ is advantageous both on their structural diversity and wide spectrum of functional groups tolerance.

The scope and generality of this CuI promoted sulfenylation of various aryl and heteroarylzinc bromides with aromatic sulfonyl chlorides/ $\mathrm{PPh}_{3}$ couple was investigated under the optimized conditions (Table 2). To $\mathrm{PhZnBr} \cdot \mathrm{LiCl} 1 \mathrm{1a}$, arylsulfonyl chlorides containing either electron-donating or electronwithdrawing groups were smoothly converted into diaryl sulfides (3a-h) in good to excellent yields. A variety of important functional groups, including nitro (3d) and cyano (3e) were well
Table 2 Reaction of arylsulfonyl chlorides with arylzinc reagents ${ }^{a, b}$

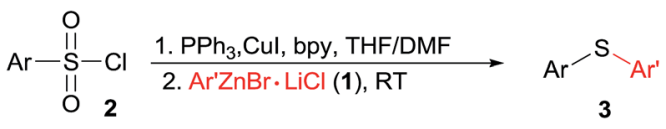

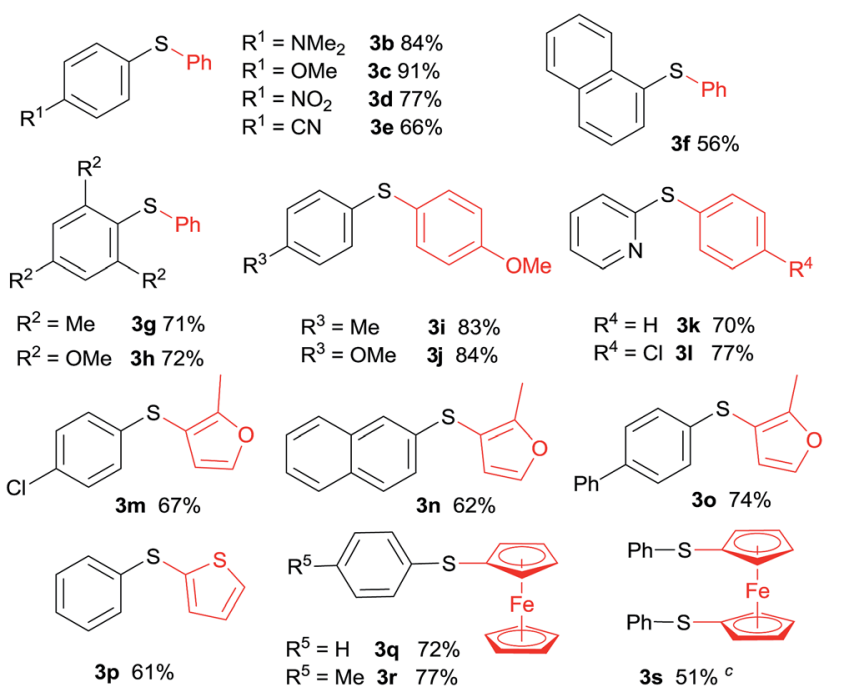

${ }^{a}$ Reaction conditions: $\mathbf{1}$ ( $\left.2 \mathrm{mmol}\right)$ in THF ( $\left.4 \mathrm{~mL}\right)$ was added into a THFDMF (5 mL, $4: 1$, v/v) solution containing CuI $(1.0 \mathrm{mmol})$, bpy $(2.0$ $\mathrm{mmol}), 2 \mathrm{a}(1.0 \mathrm{mmol})$ and $\mathrm{PPh}_{3}(2.2 \mathrm{mmol})$ under argon atmosphere and was then stirred at room temperature overnight. ${ }^{b}$ Isolated yields. ${ }^{c}$ Biszincation of ferrocene $(1.0 \mathrm{mmol})$ was performed using $n$ butyllithium $(2.2 \mathrm{mmol})$ and $\mathrm{ZnCl}_{2}(2.0 \mathrm{mmol})$.

tolerated under this optimized reaction conditions. The steric hindrance effect of this reaction was not obvious; 2,6-disubstituted arylsulfonyl chlorides could participate this transformation, giving the sulfide products $(3 \mathbf{g}, 3 \mathbf{h})$ in good yields. Heteroaromatic sulfides containing furan (3m-3o), thiophene (3p) and ferrocene (3q-3s) moieties can be easily prepared from corresponding organozinc bromides in good isolated yields.

The application of aliphatic organozinc reagents with various aromatic sulfonyl chlorides was then investigated (Table 3). Gratifyingly, a range of aliphatic organozinc reagents, both commercial available dialkylzinc reagents $(\mathbf{5 a}-\mathbf{c}, \mathbf{5 h}, \mathbf{5 k}$ and 5l) and aliphatic organozinc halides, prepared by $\mathrm{ZnCl}_{2}$ mediated transmetalation of Grignards or organolithium reagents, were compatible with the developed conditions. Notably, adamantyl thioether $\mathbf{5 n}$ was also successfully prepared using adamantylzinc bromide in $45 \%$ yield. Allylic and benzylic thioethers (5m, 5o-5q) were easily prepared using allyl or benzylzinc bromides in good yields. Also of note are thioethers $\mathbf{5 r}$ and $\mathbf{5 s}$ were readily prepared in high yields via Reformasky type reaction. Zinc acetylides (in situ formed via zincation of terminal akynes by $\mathrm{Et}_{2} \mathrm{Zn}$ ) were successfully employed to form alkynylsulfides in good yields (5t and $\mathbf{5 u}$ ).

The halogen/magnesium exchange reaction ${ }^{29}$ and the direct deprotonative metalation ${ }^{30}$ of arenes or heteroarenes with strong bases are now recognized as powerful method for highly functionalized organometallic reagents preparation. In this respect, iodobenzene bearing an electron-withdrawing $\mathrm{CF}_{3}$ 
Table 3 Reaction of arylsulfonyl chlorides with aliphatic organozinc reagents ${ }^{a, b}$

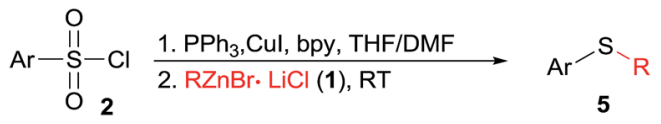

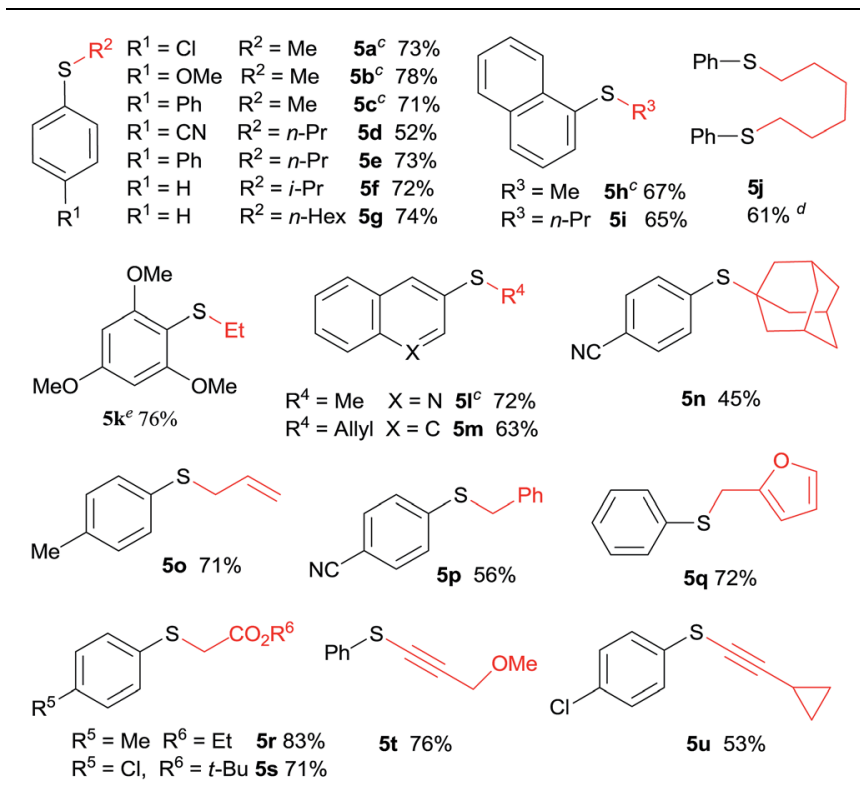

${ }^{a} \mathbf{1}(2 \mathrm{mmol})$ in THF (4 mL) was added into a THF-DMF ( $\left.5 \mathrm{~mL}, 4: 1, \mathrm{v} / \mathrm{v}\right)$ solution containing $\mathrm{CuI}(1.0 \mathrm{mmol})$, bpy $(2.0 \mathrm{mmol}), 2 \mathrm{a}(1.0 \mathrm{mmol})$ and $\mathrm{PPh}_{3}(2.2 \mathrm{mmol})$ under argon atmosphere and was then stirred at room temperature overnight. ${ }^{b}$ Isolated yields. ${ }^{c} \mathrm{Me}_{2} \mathrm{Zn}(4 \mathrm{mmol})$ was used. ${ }^{d}$ 1,6-Dibromozinc hexane $(0.5 \mathrm{mmol})$ was used. ${ }^{e} \mathrm{Et}_{2} \mathrm{Zn}(4 \mathrm{mmol})$ was used.

substituent found difficulty in direct magnesium insertion. ${ }^{31}$ Nevertheless, treatment of 4-iodotrifluorobenzene 6 by turbo Grignards $(i-\mathrm{PrMgCl} \cdot \mathrm{LiCl})^{32}$ and then transmetalated with $\mathrm{ZnCl}_{2}$ afforded the corresponding organozinc reagents, which reacted with 4-methoxybenzenesulfonyl chloride $/ \mathrm{PPh}_{3}$, giving sulfide $7 \mathbf{a}$ in $74 \%$ yield (Scheme 2). Similarly, dimethyl 4,4'thiodibenzoate $\mathbf{7 b}$ was prepared in $82 \%$ yield. Furthermore, zincation of benzo $[d]$ oxazole 8 with $\mathrm{TMPZnCl} \cdot \mathrm{LiCl}^{33}$ and then reaction with 3,4,5-trimethoxybenzenesulfonyl chloride $/ \mathrm{PPh}_{3}$ couple yielded the sulfide 9 in $71 \%$ yield.

To illustrate a possible mechanism for this transformation, some control experiments were conducted (Scheme 3). When $p$ tolylsulfonyl chloride 2a was treated with $\mathrm{PhZnBr} \cdot \mathrm{LiCl} \mathbf{1 a}$ at the same reaction without $\mathrm{PPh}_{3}$, sulfone 10 was obtained in 63\% isolated yield and sulfide $\mathbf{3 a}$ was not detected at all (Scheme 3a), indicating that $\mathrm{PPh}_{3}$ was the only reductant. However, $\mathrm{PPh}_{3}$ could not reduce sulfone $\mathbf{1 0}$ at room temperature in THF/DMF $(5: 1, \mathrm{v} / \mathrm{v})$. When diphenyl disulfide $11(1 \mathrm{mmol})$ instead of phenylsulfonyl chloride/ $\mathrm{PPh}_{3}$ was used in reaction with 4methoxyphenylzinc bromide $\mathbf{1 b}$, sulfide $3 \mathbf{c}$ was obtained in $94 \%$ isolated yield, indicating that diaryl disulfide in situ formed by reduction of sulfonyl chlorides and $\mathrm{PPh}_{3}$ were the reactive intermediates (Scheme 3b). Interestingly, treatment of 4-chlorophenylzinc iodide $1 \mathrm{c}$ (1 equiv.) with mixed disulfide 12 (1
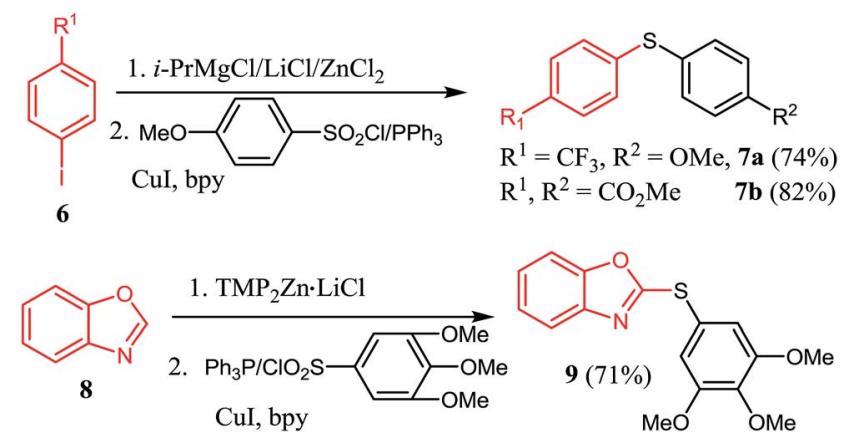

Scheme 2 Reaction of organozinc reagents delivered via Mg/l exchange reaction and deprotonation method.

(a)

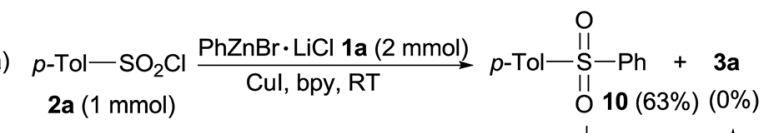

(b)

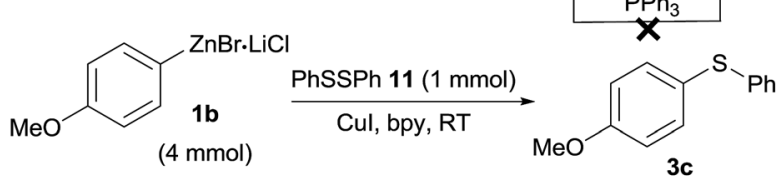

(c)
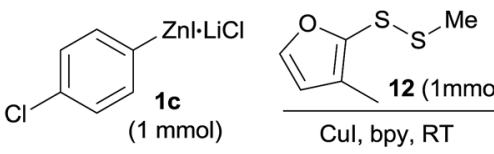

(94\%)

(1 mmol)

(d) $1 \mathrm{~b}$

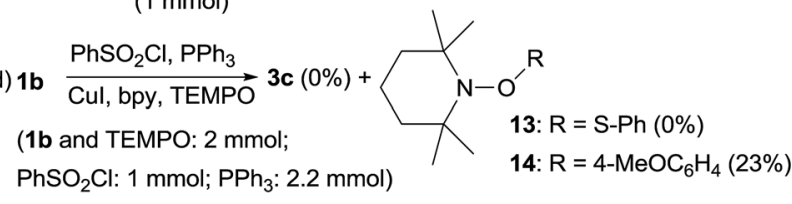

Scheme 3 Some control experiments.

equiv.) gave sulfides $3 \mathrm{~m}$ and $5 \mathrm{a}$ in exactly $1: 1$ ratio along with quantitative remaining of $\mathbf{1 2}$ according to crude ${ }^{1} \mathrm{H}$ NMR analysis, addressing a radical mechanism of this reaction as in a nucleophilic displacement reaction, $3 \mathbf{m}$ and $5 \mathbf{a}$ will be formed in different ratio owing to the unsymmetric structure nature of the mixed disulfide 12. The significant difference between organozinc reagents and Grignard reagents was also highlighted here as Grignards normally nucleophilically cleave S-S bond of disulfides and leaving another part of disulfide as thiol by-product. Furthermore, when a radical scavenger, 2,2,6,6tetramethyl-1-piperidinyloxyl (TEMPO, 2 equivalent) was added into the sulfenylation reaction of 4-methoxyphenylzinc bromide 1b (2 equiv.) with phenylsulfonyl chloride (1 equiv.), sulfide $3 \mathbf{c}$ was not produced (Scheme 3d). Meanwhile, adduct (13) of the thiyl radical ${ }^{34}$ with TEMPO was also not obtained. TEMPO was totally decomposed by organozinc reagents, leaving disulfide $\mathbf{4 a}$ untouched, whereas adduct (14) of $\mathbf{1 b}$ with TEMPO was obtained in 23\% yield (GC-MS analysis).

Based on aforementioned experimental facts, a plausible mechanism was proposed (Scheme 4). Arylsulfonyl chloride (I) was reduced by $\mathrm{PPh}_{3}$ to give diaryl disulfide (II). ${ }^{19}$ 


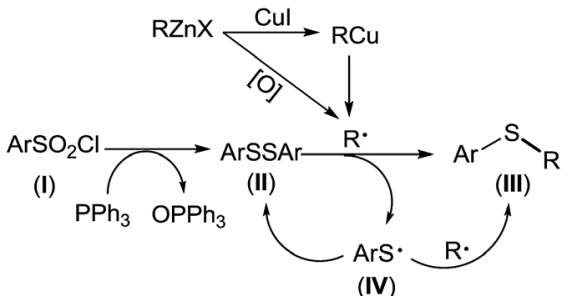

Scheme 4 Proposed mechanism

Transmetalation of RZnX with CuI gave the organocopper reagents $\mathrm{RCu}^{35}$ which underwent a homolytic dissociation to generate a $\mathrm{R}^{\cdot}$ radical. $^{36}$ It should be noted here that $\mathrm{R}^{\cdot}$ radical can also be generated from organozinc reagents in presence of trace amount of oxygen. ${ }^{37}$ Disulfide (II) captured $\mathrm{R}^{*}$ radical to form thioether (III). Meanwhile, a thiyl radical (IV) was produced which either underwent homocoupling to regenerate the disulfide (II) or was captured by another $\mathrm{R}^{\circ}$ radical to give thioether (III).

\section{Conclusion}

In summary, we have developed an efficient and practical method for the preparation of aromatic sulfides based on $\mathrm{CuI}$ promoted reaction of organozinc reagents with aromatic sulfonyl chlorides. This reaction initiated via a alkyl/aryl radical generated from organozinc reagents rather than thiyl radical generated from diaryl disulfides. A plausible reaction mechanism has been given on the basis of the control experiments.

\section{Acknowledgements}

The authors are grateful for financial support from the National Natural Science Foundation of China (No. 21262030, 20962017).

\section{References and Notes}

1 For recent reviews: (a) A. Ghaderi, Tetrahedron, 2016, 72, 4758; (b) X.-Q. Pan, J.-P. Zou, W.-B. Yi and W. Zhang, Tetrahedron, 2015, 71, 7481; (c) C. Shen, P. Zhang, Q. Sun, S. Bai, T. S. Andy Hor and X. Liu, Chem. Soc. Rev., 2015, 44, 291; (d) X. Zhu and S. Chiba, Chem. Soc. Rev., 2016, 45, 4504.

2 J. T. Reeves, K. Camara, Z. S. Han, Y. Xu, H. Lee, C. A. Busacca and C. H. Senanayake, Org. Lett., 2014, 16, 1196.

3 D. J. C. Prasad and G. Sekar, Org. Lett., 2011, 13, 1008.

4 (a) Z. Qiao, J. Wei and X. Jiang, Org. Lett., 2014, 16, 1212; (b) X.-Q. Chu, X.-P. Xu and S.-J. Ji, Chem.-Eur. J., 2016, 22, 14181; (c) A. Rostami, A. Rostami and A. Ghaderi, J. Org. Chem., 2015, 80, 8694.

5 M. Cai, R. Xiao, T. Yan and H. Zhao, J. Organomet. Chem., 2014, 749, 55.

6 (a) P. Zhao, H. Yin, H. Gao and C. Xi, J. Org. Chem., 2013, 78, 5001; (b) H. Firouzabadi, N. Iranpoor and A. Samadi, Tetrahedron Lett., 2014, 55, 1212.

7 (a) N. Singh, R. Singh, D. S. Raghuvanshi and K. Nand Singh, Org. Lett., 2013, 15, 5874; (b) F.-L. Yang, F.-X. Wang,
T.-T. Wang, Y.-J. Wang and S.-K. Tian, Chem. Commun., 2014, 50, 2111.

8 F. Luo, C. Pan, L. Li, F. Chen and J. Cheng, Chem. Commun., 2011, 47, 5304.

9 T. Hostier, V. Ferey, D. G. Pardo and J. Cossy, Org. Lett., 2015, 17, 3898.

10 Q. Wu, D. Zhao, X. Qin, J. Lana and J. You, Chem. Commun., 2011, 47, 9188.

11 D. Wang, S. Guo, R. Zhang, S. Lin and Z. Yan, RSC Adv., 2016, 6, 54377.

$12 \mathrm{X} . \mathrm{Yu}, \mathrm{Q} . \mathrm{Wu}, \mathrm{H}$. Wan, Z. Xu, X. Xu and D. Wang, RSC Adv., 2016, 6, 62298.

13 Y. Wang, X. Zhang, H. Liu, H. Chen and D. Huang, Org. Chem. Front., 2017, 4, 31.

14 (a) Z. Rappoport and I. Marek, The Chemistry of Organozinc Compounds: $R-Z n$, Wiley, Chichester, UK, 2006; (b) P. Knochel and P. Jones, Organozinc Reagents: A Practical Approach, Oxford University Press, Oxford, 1999; (c) E. Erdik, Organozinc Reagents in Organic Synthesis, CRC, New York, 1996; (d) A. D. Dilman and V. V. Levin, Tetrahedron Lett., 2016, 57, 3986.

15 I. M. Yonova, C. A. Osborne, N. S. Morrissette and E. R. Jarvo, J. Org. Chem., 2014, 79, 1947.

16 (a) B. N. Rocke, K. B. Bahnck, M. Herr, S. Lavergne, V. Mascitti, C. Perreault, J. Polivkova and A. Shavnya, Org. Lett., 2014, 16, 154; (b) N. Margraf and G. Manolikakes, J. Org. Chem., 2015, 80, 2582.

17 Y. Fu, W. Zhu, X. Zhao, H. Hügel, Z. Wu, Y. Su, Z. Du, D. Huang and Y. Hu, Org. Biomol. Chem., 2014, 12, 4295.

18 (a) Y. Fu, Y. Liu, Y. Chen, H. M. Hügel, M. Wang, D. Huang and Y. Hu, Org. Biomol. Chem., 2012, 10, 7669; (b) Y. Fu, $\mathrm{X}$. Hu, Y. Chen, Y. Yang, H. Hou and Y. Hu, Synthesis, 2012, 44, 1030; (c) Y. Fu, X.-L. Zhao, H. Hügel, B. Hou, D. Huang and Z. Du, Curr. Org. Chem., 2015, 19, 2324; (d) Y. Fu, X. L. Zhao, H. Hügel, D. Huang, Z. Du, K. Wang and Y. Hu, Org. Biomol. Chem., 2016, 14, 9720.

19 (a) G. W. Kabalka, M. S. Reddy and M.-L. Yao, Tetrahedron Lett., 2009, 50, 7340; (b) D. Wan, Y. Yang, X. Liu, M. Li, S. Zhao and J. You, Eur. J. Org. Chem., 2016, 55.

20 K. Kobayashi and Y. Kondo, Org. Lett., 2009, 11, 2035.

21 (a) H. Wuyts, Bull. Soc. Chim. Fr., 1906, 166; (b) A. J. Parker and N. Kharasch, Chem. Rev., 1959, 59, 583; (c) S. Munavalli, D. I. Rossman, D. K. Rohrbaugh and C. P. Ferguson, J. Fluorine Chem., 1993, 61, 147.

22 S. Munavalli, D. I. Rossman, D. K. Rohrbaugh and C. P. Ferguson, J. Fluorine Chem., 1993, 61, 155.

23 P.-S. Luo, M. Yu, R.-Y. Tang, P. Zhong and J.-H. Li, Tetrahedron Lett., 2009, 50, 1066.

24 S. Yasuike, M. Nishioka, N. Kakusawa and J. Kurita, Tetrahedron Lett., 2011, 52, 6403.

25 D. I. Rossman, D. K. Rohrbaugh, C. Parker Ferguson and L. J. Szafraniec, J. Fluorine Chem., 1992, 59, 91.

26 Y. Matano, T. Miyamatsu and H. Suzuki, Organometallics, 1996, 15, 1951.

27 A. S.-Y. Lee, Y.-T. Chang, S.-F. Chu and K.-W. Tsao, Tetrahedron Lett., 2006, 47, 7085. 
28 S. S. Ashirbaev, V. V. Levin, M. I. Struchkova and A. D. Dilman, J. Fluorine Chem., 2016, 191, 143.

29 (a) A. Krasovskiy and P. Knochel, Angew. Chem., Int. Ed., 2004, 43, 3333; (b) R. L. Y. Bao, R. Zhao and L. Shi, Chem. Commun., 2015, 51, 6884.

30 (a) B. Haag, M. Mosrin, H. Ila, V. Malakhov and P. Knochel, Angew. Chem., Int. Ed., 2011, 50, 9794; (b) D. Seyferth, Organometallics, 2009, 28, 2.

31 J. L. Leazer Jr, R. Cvetovich, F.-R. Tsay, U. Dolling, T. Vickery and D. Bachert, J. Org. Chem., 2003, 68, 3695.

32 D. Hauk, S. Lang and A. Murso, Org. Process Res. Dev., 2006, 10, 733 .
33 D. Haas, M. Mosrin and P. Knochel, Org. Lett., 2013, 15, 6162.

34 (a) X. Zhu, P. Li, Q. Shi and L. Wang, Green Chem., 2016, 18, 6373; (b) X. Zhu, X. Xie, P. Li, J. Guo and L. Wang, Org. Lett., 2016, 18, 1546.

35 P. Knochel and R. D. Singer, Chem. Rev., 1993, 93, 2117.

36 (a) N. J. Rijs, N. J. Brookes, R. A. J. O'Hair and B. F. Yates, J. Phys. Chem. A, 2012, 116, 8910; (b) H. Gilman, R. G. Jones and L. A. Woods, J. Org. Chem., 1952, 17, 1630.

37 F. Denes, S. Cutri, A. Perez-Luna and F. Chemla, Chem.-Eur. J., 2006, 12, 6506. 